\title{
IS COLONY ATTENDANCE BY SHEARWATERS INFLUENCED BY BRIGHT MOONLIGHT OR INCLEMENT WEATHER?
}

\author{
by Christopher Powell, Stuart Bradley and Ron Wooller
}

(with four text-figures and one table)

\begin{abstract}
Powell, C., Bradley, S. \& Wooller, R. 2008 (31:x): Is colony attendance by shearwaters influenced by bright moonlight or inclement weather? Papers and Proceedings of the Royal Society of Tasmania 142(1): 35-44.

https://doi.org/10.26749/rstpp.142.1.35 ISSN 0080-4703. Department of Biological Sciences and Biotechnology,

Murdoch University, South Street, Murdoch, Western Australia 6150 (CP, SB, RW); Department of Agriculture and Food, PMB 50, Esperance, Western Australia $6450\left(\mathrm{CP}^{*}\right)$. *Author and address for correspondence. Email: cpowell@agric.wa.gov.au
\end{abstract}

\begin{abstract}
If nocrurnal colony attendance is associated with avoidance of predators, fewer nests would be visited by parent shearwaters on moonlit nights, or nests would be visited later, than on dark nights. Additionally, if shearwaters foraged at night on certain prey species, feeds delivered to nestlings would be larger on dark nights. We found that feed size and the probability of a nest visit were both greater on moonlit nights, while food delivery after midnight was not. A minimal risk of predation concurs with the disregard for moonlight shown by Flesh-footed Shearwaters, Puffinus carneipes, but does not explain their apparent preference for it. While nocturnal foraging is unlikely, it is not clear why feeds were significantly larger on moonlit nights, or why colony attendance by this species is strictly nocturnal. Weather may impact the ability of seabirds to forage at sea, although this is difficult to confirm. It was likely that nest attendance by parent shearwaters would be lower if certain variables negatively influenced foraging, but such influences may not manifest themselves immediately. Nest visits were examined in relation to local weather conditions at time-lag intervals of up to seven days. While no significant cross correlations were determined between burrow entry and two wind-velocity variables, a significant positive correlation was determined when the study sire experienced pronounced unseasonal rainfall events.
\end{abstract}

Key Words: colony attendance, moonlight, procellariiforms, shearwaters, Puffinus carneipes, wind, rainfall, Woody Island.

\section{INTRODUCTION}

The day-to-day behaviour of pelagic seabirds is poorly known because of the difficulties associated with studying them at sea. Accordingly, most knowledge is derived from data collected at the colony when the birds return to breed. Several procellariiforms (albatross, shearwater and other petrel species) are reportedly less numerous at their breeding colonies on clear, moonlit nights than on overcast or otherwise dark nights (Warham 1960, Harris 1974, Imber 1975, Watanuki 1986). Others have been shown to exhibit different behaviour in arriving at their nests later on moonlit nights (Storey \& Grimmer 1986, Klomp \& Furness 1992). These observations have been interpreted as a response to increased risks of predation and/or disturbance, together with limited or generally ineffective means of defence (Corkhill 1973, Watanuki 1986, Furness 1987).

However, contrary to these findings, Manuwal (1974) observed fewer birds on very dark nights. Similarly, whilst Storey \& Grimmer (1986) noted high burrow activity on darker nights, the incidence of aerial vocalisation and courting behaviour on the ground was very much reduced and comparable to activity levels on the brightest nights. Corkhill (1973) suggested that gulls preyed upon Manx Shearwaters, Puffinus puffinus Brunnich, 1764, more intensively on moonlit nights because visibility was better, but that predation was higher on very dark nights than on nights of intermediate illumination because shearwaters were disoriented in dark conditions and more often landed near gull nests by accident. Harris (1969) discussed the colony attendance of two similar-sized species of storm-petrel that nested on the Galapagos Islands; one nocturnal and the other diurnal. The same attendance behaviour has also been reported in Cory's Shearwater, Calonectris diomedea borealis (Scopoli, 1769), breeding at two Atlantic colonies (Hamer
\& Read 1987, Klomp \& Furness 1992), whilst McNeil et al. (1993) emphasised that some species maintained nocturnal nest attendance even in the absence of predation. Such observations suggest that predator avoidance is not a universal explanation for the avoidance of bright moonlight. Alternatively, colony visitation and chick provisioning may be influenced by the effect of ambient light conditions on prey availability close to the surface of the sea (Imber 1975). Bioluminescence and diel-vertical migratory behaviour of certain cephalopods (squid) found in some procellariiform regurgitates have supported the argument that certain species feed at night; supposedly because such prey are only visible and accessible near the surface at this time (Imber 1973, Clarke et al. 1981, Weimerskirch \& Wilson 1992). This implies that overall food delivery would be lower on moonlit nights because prey are less available, whereas the anti-predator hypothesis predicts that the proportion of nests visited would be lower, but the size of feeds no smaller (Klomp \& Furness 1992).

Climatic impacts upon seabirds have undoubtedly helped shape their demography and life-history characteristics. While severe perturbations occasionally result in large-scale mortalities (Schreiber 2002), the continuous rebalancing of the Earth's heat load is of ten responsible for extreme local weather conditions, the full gamut of which must be encountered by wide-ranging seabirds, particularly those that forage in the Southern Ocean (Brooke 2004). Weather may have an impact on the ability of seabirds to forage due to direction and velocity of wind affecting flight, the clarity/turbidity of water affecting their ability to identify and capture prey, as well as larger scale effects upon prey behaviour and distribution (Dunn 1973, Taylor 1983, Sagar \& Sagar 1989, Finney et al. 1999). Like many aspects of seabird biology, the effects of weather upon seabirds at sea are poorly known because most information is gleaned at the 
breeding colony. Warham (1960) proposed that the general state of the weather preceding the night in question, would have some effect on the numbers of adult shearwaters that came ashore to feed their young. However, from his study of Short-tailed Shearwaters, Puffinus tenuirostris (Temminck, 1835), breeding in Tasmania, he found no correlations between rainfall, or wind strength and direction, and nightly burrow visitation by parents.

In this paper we make a similar investigation of the same weather variables at time-lag intervals of up to seven days, and compare nest visitation between moonlit and dark nights. Specifically, we investigated whether parent shearwaters avoided returning to the colony on moonlit nights, or whether they delayed their return until after the moon had set. Additionally, we examined the influence of moonlight on the sizes of feeds delivered to chicks.

\section{METHODS}

\section{The study species, the field site and data collection}

From 2000-03 the Flesh-footed Shearwater, Puffinus carneipes Gould, 1844, a procellariiform seabird, was studied in the centre of its western range at a small colony on Woody Island (33 $\left.58^{\prime} \mathrm{S}, 122^{\circ} 01^{\prime} \mathrm{E}\right)$, Western Australia. This shearwater breeds in burrows at three distinct locations on the island, where adult birds make landfall after dark. There are no snakes or indigenous mammals on Woody Island; the Black Rat, Rattus rattus alexandrinus (Linnaeus, 1758), being the only potential terrestrial predator. However, large predatory birds include the Australian Raven, Corvus coronoides Vigors \& Horsfeld, 1827, Pacific Gull, Larus pacificus Latham, 1802, and White-bellied Sea Eagle, Haliaeetus leucogaster (J.F. Gmelin, 1788).

Shearwater burrows were monitored daily using knockdown barricades, from mid-October, when adult birds returned to the colony, through to early May the following year, when the last fledglings departed. Twenty chicks were weighed once-daily over the three months they spent in the nest (Powell et al. 2007). During each year, food delivery was calculated by weighing a randomly selected sub-sample of ten chicks, every three hours between dusk and dawn, over seven-night intervals, at different stages of the nestling period (Hamer et al. 1997, Phillips \& Hamer 2000).

The first weighing session commenced before dusk each evening, and the final session, 12 hours later, after dawn the following morning. Food delivery was recorded only when the barricade was displaced, and the chick exhibited a mass increase between weighings. Displaced barricades coinciding with no mass increase were attributed to factors other than chick provisioning, and were excluded from the analysis. Total overnight food delivery equalled the sum of positive mass increments between successive weighings. Frequent weighing trials conducted during February and March 2000 and February, March and April 2003, coincided with either a full moon or near-full moon when the moon rose shortly after sunset, and set around sunrise the following day. Thus, during clear weather there was bright moonlight over the colony for all or most of the night. By contrast, during nights of inclement weather or heavy cloud (which were common), the moon was obscured and no direct moonlight reached the colony. Burrow visitation was examined to determine whether ambient light influenced colony attendance by adult shearwaters. Nights of full moon with obscured moonlight were preferred to dark nights at other phases of the moon, or diurnal moonrise, to exclude any unknown astronomical influences.

To investigate whether moonlight increased the tendency of parents to visit their nests later (Storey \& Grimmer 1986, Klomp \& Furness 1992), nest visitation before and after midnight was also examined. Further, in addressing the hypothesis that feeds would be smaller on moonlit nights, in line with Imber (1975), food delivery to nestlings was compared between nights of bright moonlight and nights of total darkness.

\section{Astronomical and climatic data}

Dates of full moon, times of moonrise and moonset, and sunrise and sunset were obtained online (Geoscience Australia 2003), while daily rainfall and three-hourly wind observations were supplied by the Bureau of Meteorology. The Esperance Meteorological Office is located some $20 \mathrm{~km}$ from Woody Island, so data may not have reflected island conditions exactly. Because three-hourly observations often exhibited considerable variation over the course of a 24 -hour period, wind data were analysed in terms of both mean and maximum velocity (in knots) recorded in each 24 -hour period from midnight, as well as the mean angle of the wind. Wind angle refers to its vector (the direction in which the wind is moving), whereas wind direction may be confused with the direction from which it is coming (e.g., a "southerly" comes from the south).

\section{Statistical analysis of data}

The means of several variables associated with food delivery were compared between moonlit and dark nights. To take into account the repeat-measures effect of feeds delivered to the same nest, burrow entry data were analysed using the logistic random-effect regression module of the Egret Statistical Package for Windows ${ }^{\mathrm{rN}}$ (CYTEL 1999). Burrow identity was used as the repeat grouping variable; and whether the nest was visited on a particular night and, whether a feed was delivered after midnight, were the binary dependent variables. Year and measuring period were included as factors to absorb annual and seasonal variation in the frequency of visits. Tests of the mass of food delivered between dark and moonlit nights were performed using the mixed-model module of the SPSS Advanced Statistical Package for Windows ${ }^{\mathrm{TM}}$ (Norušis 1994). Burrow identity was treated as the subject variable of the repeat-measures model; and year, month and day within measuring periods were treated as the repeated effects. Moonlit versus dark nights was treated as a fixed factor.

To calculate wind angle, it was necessary to transform vectors in degrees to radians, for calculation as polar coordinates, before re-transformation to allow presentation of data relative to degrees (Zar 1999). The Axum 5.0B Package for Windows ${ }^{\text {Ts }}$ (MathSoft 1996) was used for this purpose, whilst time-lag correlations and other statistical analyses were performed using the SPSS Advanced Statistical Package for Windows ${ }^{\mathrm{TM}}$ (Norušis 1994). Time-lag cross correlations were used to detect daily changes (transform difference $=1$ ) in nest visitation as a result of rainfall and changes in wind conditions at lag intervals of up to seven days (i.e., whether rainfall or wind influenced daily changes in the proportion of nests visited for up to seven days before, and seven days after those particular weather conditions). Significance was 
determined if the cross correlation function exceeded the confidence limits ( \pm two standard errors from zero).

\section{RESULTS}

\section{Moonlight, burrow visitation and food delivery}

Although the main influx of shearwaters typically occurred shortly after sunset, observations at the colony, and mass increases recorded during consecutive weighing sessions, revealed that birds arrived at the nesting area throughout the night. Table 1 shows 23 nights in total, of full moon ( \pm up to three nights) when bright moonlight shone over the colony, and full moon ( \pm up to four nights) when the moon was obscured and the colony was in darkness. Also, shown are the times (corrected for local time) of sunrise and sunset, and moonrise and moonset (Geoscience Australia 2003), as well as observations of conditions at the colony.

Using logistic random-effect regression with burrow identity as the grouping variable, and including year and month as factors, we determined that there was significantly greater probability of burrows being visited on moonlit nights than on dark nights (deviance difference $\chi^{2}{ }_{1}=8.923$, $\mathrm{p}=0.003$, odds ratio $=1.77$ ). In other words: moonlight increased the ratio of the odds of a visit (as opposed to no visit) by a factor of $77 \%$, all other factors being equal. Initially, there was also a significantly greater probability of meals being delivered after midnight on moonlit nights (deviance difference $\chi^{2}{ }_{1}=10.169, \mathrm{p}=0.001$, odds ratio $=2.08$ ). However, when the regression was restricted to burrow nights where a visit was recorded, and the dependent variable was simply the occurrence of a visit after midnight; the presence of moonlight was not significant; indicating that, overall, moonlight did not produce significant changes in the probability of a visit occurring after midnight rather than before. Finally, feed size (the mean mass of food delivered overnight) was greater, by a highly significant margin, on moonlit nights ( $81.2 \mathrm{~g} \pm 7.2$ standard error) than on dark nights $(71.5 \mathrm{~g} \pm 6.6$ standard error) when analysed using a repeat-measures mixed model $\left(\mathrm{F}_{2,88}=\right.$ 123.181, $\mathrm{p}=<0.001$ )

\section{Rainfall and wind characteristics}

A significant correlation between nest visitation and rainfall was determined in 2000 , when two pronounced rainfall events occurred. In late February over $70 \mathrm{~mm}$ of rain fell in 24 hours, followed by a deluge of similar proportions over 48 hours, two weeks later in March. The second event

TABLE 1

Dates of full moon during 2000 and 2003. Times of sunrise/sunset, moonrise/moonset and observations of ambient light at the colony

\begin{tabular}{|c|c|c|c|c|c|c|}
\hline Moon & Date & Sunrise & Sunset & Moonrise & Moonset & Observations at colony \\
\hline Waxing ${ }^{3}$ & $17 / 2 / 2000$ & 0528 & 1844 & 1658 & 0224 & Clear; bright moonlight (gone from colony by 0130 ) \\
\hline Full & $20 / 2 / 2000$ & 0531 & 1840 & 1918 & 0545 & Clear; bright moonlight (gone from colony by 0445 ) \\
\hline Waxing ${ }^{3}$ & $17 / 3 / 2000$ & 0553 & 1808 & 1630 & 0221 & Clear; bright moonlight (gone from colony by 0120 ) \\
\hline Waxing ${ }^{2}$ & $18 / 3 / 2000$ & 0554 & 1806 & 1712 & 0327 & Clear; bright moonlight (gone from colony by 0230 ) \\
\hline Waxing $^{1}$ & $19 / 3 / 2000$ & 0555 & 1805 & 1750 & 0433 & Clear; bright moonlight (gone from colony by 0030 ) \\
\hline Waning ${ }^{2}$ & $18 / 2 / 2003$ & 0529 & 1842 & 1954 & 0628 & Clear; bright moonlight \\
\hline Waning ${ }^{3}$ & $19 / 2 / 2003$ & 0530 & 1841 & 2026 & 0738 & Clear; bright moonlight after 2300 \\
\hline Waxingl & $17 / 3 / 2003$ & 0552 & 1809 & 1748 & 0404 & Clear before 2330; rain after \\
\hline Waning 1 & $19 / 3 / 2003$ & 0554 & 1806 & 1855 & 0626 & Clear \\
\hline Waxing 2 & $14 / 4 / 2003$ & 0614 & 1731 & 1616 & 0250 & Patchy doud; moonlight \\
\hline Waxing ${ }^{1}$ & $15 / 4 / 2003$ & 0614 & 1730 & 1649 & 0400 & Intermittent light cloud; moonlight \\
\hline Full & $16 / 4 / 2003$ & 0615 & 1729 & 1722 & 0511 & Clear; bright moonlight \\
\hline Waxing ${ }^{2}$ & $18 / 2 / 2000$ & 0529 & 1843 & 1751 & 0330 & Dark; heavy cloud, no moonlight \\
\hline Waxing $^{1}$ & $19 / 2 / 2000$ & 0530 & 1842 & 1837 & 0437 & Dark; heavy cloud, no moonlight \\
\hline Waxing 3 & $16 / 3 / 2000$ & 0552 & 1809 & 1543 & 0116 & Thunderstorm; heavy cloud, no moonlight \\
\hline Waxing ${ }^{4}$ & $14 / 2 / 2003$ & 0526 & 1847 & 1707 & 0200 & Overcast; only occasional moonlight \\
\hline Waxing ${ }^{2}$ & $15 / 2 / 2003$ & 0527 & 1846 & 1756 & 0302 & Overcast, drizzle, no moonlight \\
\hline Full & $16 / 2 / 2003$ & 0529 & 1843 & 1840 & 0409 & Heavy cloud, rain, no moonlight \\
\hline Waning $^{4}$ & $20 / 2 / 2003$ & 0531 & 1840 & 2059 & 0847 & Thunder, rain, heavy cloud, no moonlight \\
\hline Full & $18 / 3 / 2003$ & 0553 & 1807 & 1822 & 0515 & Heavy cloud; moon intermittent after 2330 \\
\hline Waning 2 & $20 / 3 / 2003$ & 0555 & 1805 & 1929 & 0737 & Clear, but colony in darkness until after 2100 \\
\hline Waning ${ }^{3}$ & $21 / 3 / 2003$ & 0555 & 1803 & 2004 & 0849 & Clear, but colony in darkness until after 2100 \\
\hline Waxing 3 & $13 / 4 / 2003$ & 0613 & 1733 & 1542 & 0141 & Heavy cloud before 2100 ; moonlight at 2345 \\
\hline
\end{tabular}

Superscript refers to the number of nights before or after full moon, e.g., Waxing ${ }^{3}=$ three before, Waning $^{2}=$ two after. 
caused flooding of burrows in low-lying areas, and resulted in some nestlings evacuating their burrow. Interestingly, rather than nest visitation being impeded, burrow attendance was $100 \%, 85 \%$ and $100 \%$ on the three respective dates of high rainfall. With the assumption that the March deluge was a single continuous event, the overall correlation for rainfall was significant and, not surprisingly, positive, at zero. In 2003, however, a single heavy downpour of $28 \mathrm{~mm}$ occurred two days after the lowest proportion of burrow entries (11\%), which created a negative lag (fig. 1). In other words, there were fewer birds in burrows two days before rainfall. Although no significant cross correlations were determined between mean or maximum wind velocity (fig. 2 ), this rainfall event coincided with the highest recorded wind velocity (Day 104, 2003; fig. 3).

No significanr correlation was determined between nest entry and mean wind angle (fig. 1), exemplified by polar plots in concurrence with maximum wind velocity (fig. 4). It was expected that, if significant correlations existed in relation to mean angle, circles would be concentrated in the outer radii (indicating higher proportions of visitation) in favoured wind conditions and, vice versa, in less-favourable conditions. Furthermore, if any significant interactive relationships existed between wind angle and wind velocity, the circles would be expected to vary in size with their placement upon polar coordinates in relation to favoured wind conditions. This was not the case in any single year. In a global plot encompassing all three years examined, a higher concentration of circles in the northerly quarter $\left(315^{\circ}-45^{\circ}\right.$, fig. 4) reconciles with the normal pattern of prevailing southeasterly summer winds, punctuated by southwesterly changes.
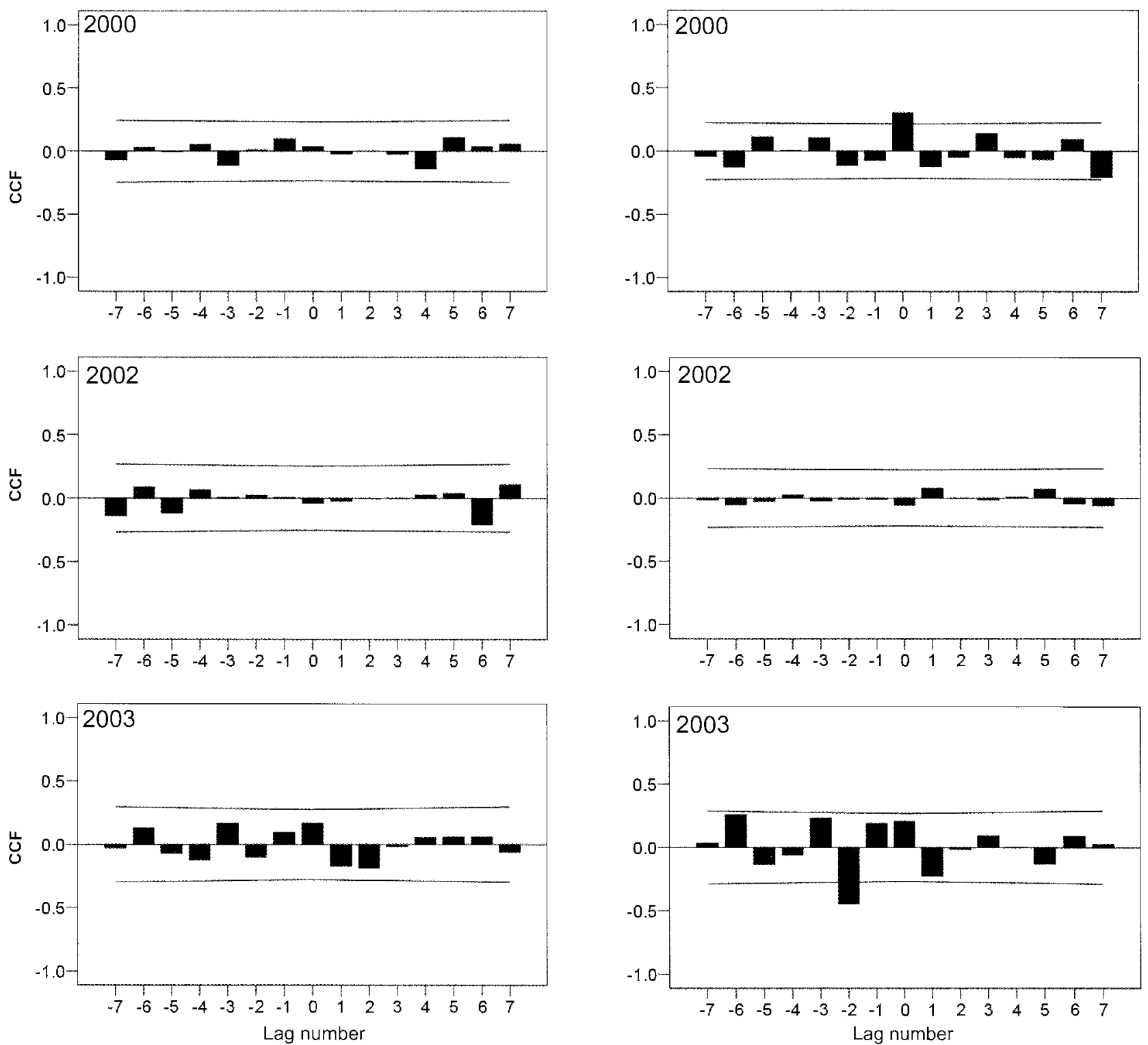

FIG. 1 - Time-lag cross correlations ( \pm 7 days) of daily changes in rainfall (right column) and mean wind angle (left column), with daily changes in the proportion of nests entered overnight. A significance correlation is determined when the cross correlation function (CCF), indicated by the black bars, exceeds the confidence limits ( \pm two standard errors from zero). A significant positive correlation at zero days was identified for rainfall in 2000 (top right), and a significant negative correlation at -2 days (boitom right). 

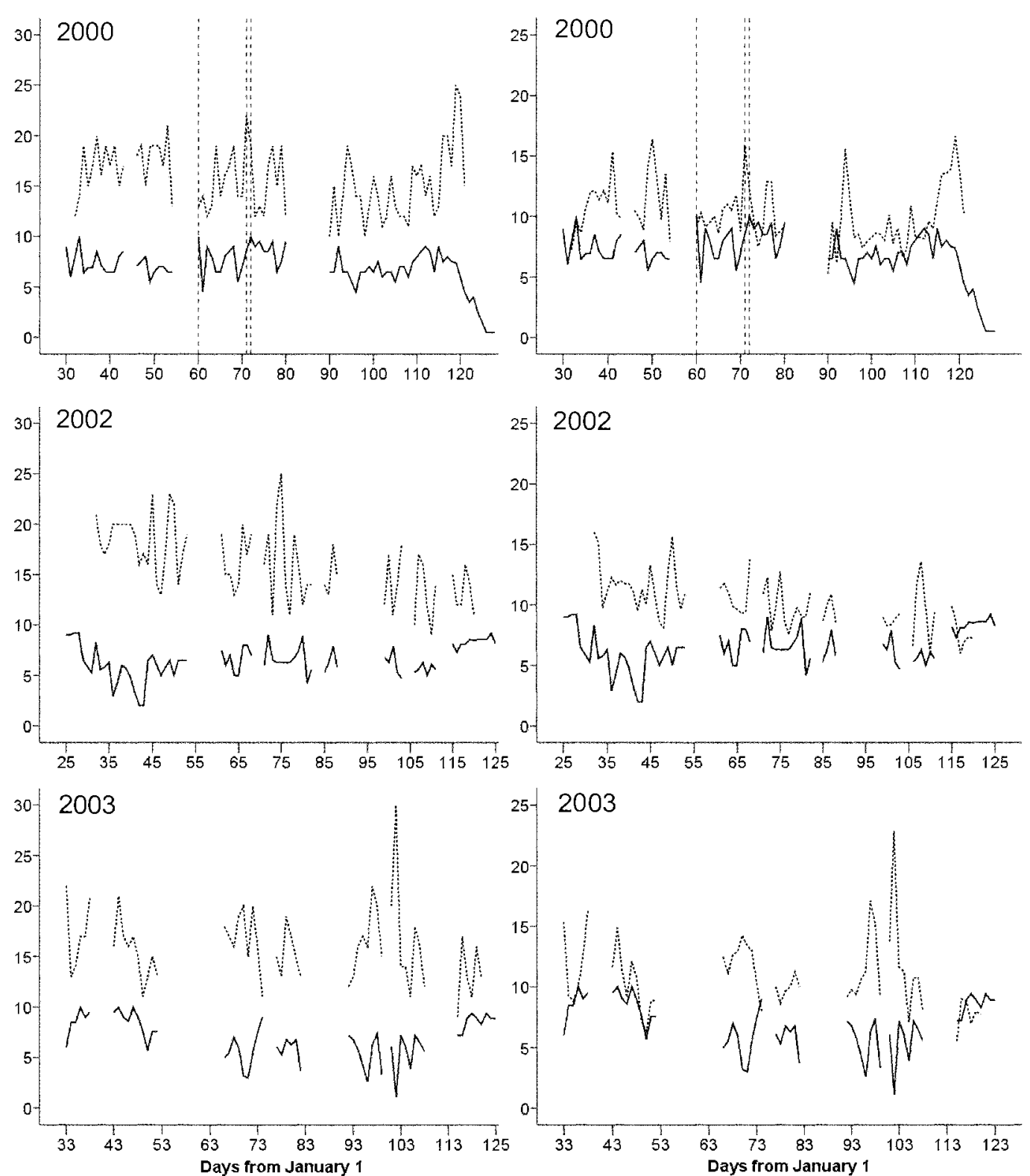

FIG.2 - Time-series plots of the proportion (multiplied by a factor of 10) of nests entered overnight (bold line) in relation to mean (right column) and maximum (left column) wind velocities (broken line) in knots. The broken vertical lines on the two figures for 2000 denote significant rainfall events during that year.

\section{GENERAL DISCUSSION}

We found no negative influence of moonlight upon colony attendance by Flesh-footed Shearwaters. To the contrary, there was a greater probability of nests being visited on moonlit nights; feeds were larger and moonlight did not change the probability of a nest being visited after midnight rather than before. Similarly, we found no negative correlations between colony attendance and inclement weather conditions. Again, to the contrary, there was a significant positive correlation between burrow visitation and heavy rainfall.

Warham (1958) reported heavy egg-loss by Flesh-footed Shearwaters on Eclipse Island to the King's Skink Egernia kingii (J.E. Gray, 1838). However, this reptile does not occur on Woody Island and, it is not known whether its smaller congener, the Southwestern Crevice Skink, E. napoleonis (Gray, 1838), preys upon eggs, even though it was known to scavenge old ones. Similarly, the impact of the introduced Black Rat is unknown; but the large-bodied adult Fleshfooted Shearwater $(625 \mathrm{~g} \pm 3$, Powell et al. 2007) is unlikely to be threatened. Both snakes and indigenous mammals are absent from the island, but Australian Ravens occasionally dug chicks from their burrows (Johnstone et al. 1990). The large predatory Pacific Gull occurs as only a few breeding pairs, and the White-bellied Sea Eagle is but an occasional visitor. Thus, predation of adult Flesh-footed Shearwaters on Woody Island is likely to be low or negligible.

Nightly observations at the colony from 2000-03 confirmed that many shearwaters arrived to feed their young around dusk or shortly thereafter. However, overnight weighing trials determined that although chicks received almost one meal per night on average (Powell et al. 2007) on many occasions both parents delivered food during the same night and, meals were delivered both before 

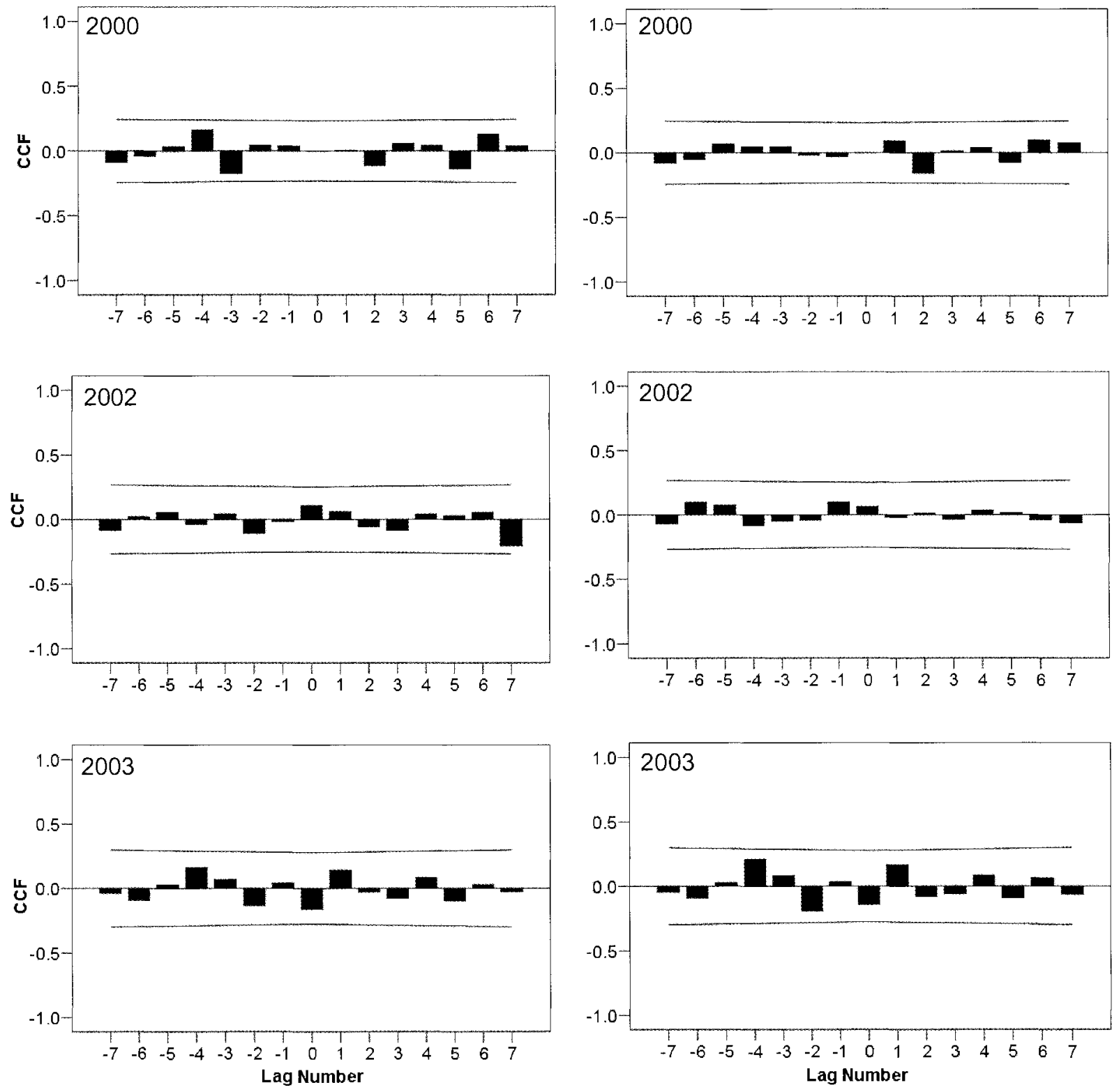

FIG. 3 - Time-lag cross correlations ( \pm 7 days) of daily changes in mean (right column) and maximum (left column) wind velocities, with daily changes in the proportion of nests entered overnight.

and after midnight. If shearwaters were less numerous at Woody Island on clear moonlit nights, it would support the hypothesis that moonlight avoidance is a response to an increased risk of predation (Corkhill 1973, Imber 1975, Watanuki 1986, Storey \& Grimmer 1986), in line with the generally nocturnal colony behaviour of Puffinus shearwaters (Warham 1990, McNeil et al. 1993). A lower proportion of burrows visited would, therefore, be expected on nights of bright moonlight than on overcast or otherwise dark nights (Klomp \& Furness 1992). Similarly, if adults were moonlight-shy there would be a greater tendency to delay returning to the colony until after moonsec (Storey \& Grimmer 1986, Klomp \& Furness 1992). In this study, nights of full moon or near-full moon with moonlight obscured were examined, rather than dark nights at other phases of the moon, to exclude unknown astronomical factors that might influence or affect prey distributions or the behaviour of the birds themselves.
Using logistic random-effect regression software designed to absorb repeat-measures effects, as well as annual and seasonal variation, we determined that on moonlit nights there was a significantly greater probability overall, of burrows being visited and, initially, a significantly greater probability of food being delivered after midnight. However, the presence of moonlight was not a significant predictor of a burrow visit occurring after midnight when the regression was restricted to burrow nights where a visit was recorded. This indicated that, overall, moonlight did not produce significant changes in the probability of a visit occurring after midnight rather than before. Fleshfooted Shearwaters, therefore, demonstrated no moonlight avoidance behaviour, which corresponds with the notion that predation on Woody Island is low or negligible. By contrast, shearwaters showed a preference for conditions of ambient illumination at the colony - possibly because it enhances visual cues. 

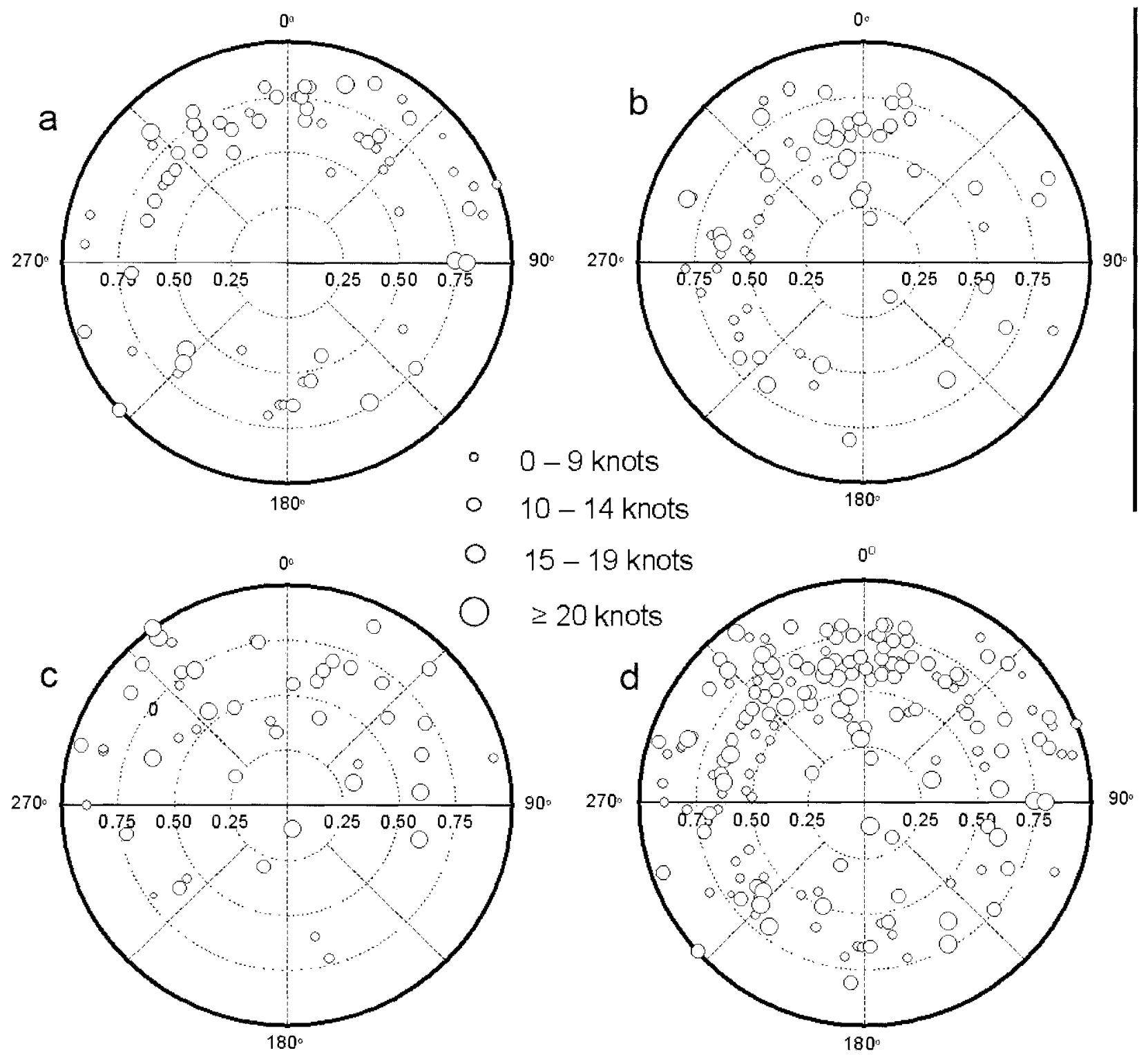

FIG. 4 - Polar plots of the nightly proportion of nests entered during (a) 2000, (b) 2002 and (c) 2003, and (d) a global plot incorporating all three years, in relation to mean wind angle and maximum wind velocity. Proportions are defined by radial lines from the centre (zero), mean angle (direction of wind movement) is relative to degrees $\left(0^{\circ}-360^{\circ}\right.$ ), and wind velocity is classified in four groups identified by open circles of increasing size.

Further to this, a repeat-measures mixed-model analysis determined that feed size (the mean mass of food delivered overnight) was greater, by a highly significant margin, on nights of bright moonlight than on dark nights. The suggestion that some procellariiforms feed at night has been supported by the fact that certain cephalopods found in seabird regurgitates, would be visible and accessible to foraging birds only when they rise to near the sea surface at night (Clarke et al. 1981, Weimerskirch \& Wilson 1992). Moreover, Gould (1967) observed Wedge-tailed Shearwaters, Puffinus pacificus (J.F. Gmelin, 1789), foraging at night, and Harper (1972) stated that Thin-billed Prions, Pachyptila belcheri (Matthews, 1912), fed mainly at night; on vertically migrating prey. Similarly, Grey-faced Petrels, Pterodroma macroptera (A. Smith, 1840), took 80\% or more prey at night, of which about $90 \%$ consisted of bioluminescent cephalopods (Imber 1973, 1975). While Cory's Shearwater chicks were fed mainly on teleost fish, they also received cephalopods; and these were light-sensitive vertical migrants that rise close to the surface only on dark nights. Consequently, meals were significantly smaller on nights of full moon, suggesting that Cory's Shearwater foraged nocturnally and, with greater success on dark nights due to a greater availability of prey (Klomp \& Furness 1992). In direct contrast, feeds delivered to Flesh-footed Shearwater chicks were of significantly greater mass on moonlit nights. Whilst detailed dietary information for this species is scarce, a stable isotope analysis of eggshell membranes determined a slight enrichment of $\delta^{13} \mathrm{C}$, and a $\delta^{15} \mathrm{~N}$ enrichment of around $4 \%$ - evidence that during the pre-laying period at least, the dominant prey was pilchard Sardinops sagax (Steindachner, 1879), a schooling teleost (J.N. Dunlop, unpubl. data). Similarly, intense fishery bycatch observations undertaken during March and April in 2007 and 2008 confirmed that scavenging by Flesh-footed Shearwaters around pilchard fishing vessels was most intense 
at the time that chicks attained peak body mass (C. Powell, unpubl. data). Nocturnal foraging on vertically migrating prey is, therefore, unlikely, but the effects of moon phase on organisms at lower trophic levels, that may in turn affect the feeding of pilchards, are unknown. A more detailed investigation will be required to provide an explanation as to why feeds were significantly larger rather than not different.

Evolution in oceanic seabirds has resulted in extremely efficient operation in the environment upon which they depend for their food. For example, long-distance foragers such as albatross (Diomedea spp.) rely on persistent winds to fully exploit their given mode of flight (Tickell $\&$ Gibson 1968). Given the not-dissimilar flap-gliding flight of shearwaters (Pennycuick 1987), it was not surprising that higher wind velocities did not result in lower proportions of nest attendance. Although the day of the greatest mean and maximum velocities ( 23 and 30 knots) occurred two days after the lowest recorded burrow entry rate (11\%), no significant correlation was determined overall. It had been expected that calm weather would result in fewer birds coming ashore, but this was not the case. While completely calm days were rare, the lowest mean wind velocities recorded (5-6 knots) coincided with nest visitation rates of $65-80 \%$. If, indeed, this population can feed relatively close to the colony, then wind energy as a component of the energy budget of prolonged foraging trips may not be as crucial as it appears for some species, and meal delivery frequency would remain high even over periods of low wind velocity. However, low burrow attendance two days preceding inclement weather events may indicate changes in foraging behaviour in anticipation of the event.

The lack of correlation between nest visitation and mean wind angle is congruent with the observation that aspect was not a significant determinant of colony location (Powell et al. 2007). The northeasterly aspect of one of the three breeding areas suggests that colonised areas are not necessarily selected in relation to the seasonal prevailing wind. Moreover, the term "mean wind angle" is itself somewhat arbitrary. By definition, it represents the calculated mean of eight threehourly observations, which may have varied considerably over the course of a 24-hour period. Each, however, is of equal importance because temporal wind conditions while adults forage at sea are likely to have a greater influence upon their foraging success than the immediate conditions at nightfall and, consequently, whether or not they return to the colony. The high concentration of nest visits that coincided with winds from the southeasterly to southwesterly quarter are likely to be a consequence of the prevailing southeasterly winds during the summer months, which are punctuated by southwesterly changes.

We conclude that Flesh-footed Shearwaters did not demonstrate moonlight avoidance behaviour at their breeding colony. To the contrary, they displayed some preference for moonlit nights, when burrows were more likely to be visited and feeds were significantly larger. Although, burrow visitation was high during pronounced rainfall events when the correlation was significant at zero, it is likely that shearwaters anticipate approaching weather and modify their foraging behaviour accordingly. Otherwise, nest visitation was not significantly influenced by rainfall, or by wind direction or velocity, at time-lag intervals of up to seven days preceding or following the event.

\section{ACKNOWLEDGEMENTS}

We thank Mackenzie's Island Cruises, Esperance, for their generous provision of transport and accommodation for this work. The study was supported by a Murdoch University Research Studentship and by the Centre for Fish and Fisheries Research at Murdoch University. The work was authorised by the Western Australian Department of Environment and Conservation, the Murdoch University Animal Ethics Committee and the Australian Bird and Bat Banding Database. CP also thanks the late Dr Irynej Skira for his friendship during the short time he knew him at the Snares Islands during January 2005.

\section{REFERENCES}

Brooke, M. de L. 2004: Albatrosses and Petrels Across the World. Oxford University Press, Oxford: 499 pp.

Clarke, M.R., Croxall, J.P. \& Prince, P.A. 1981: Cephalopod remains in regurgitations of the Wandering Albatross Diomedea exulans at South Georgia. British Antarctic Survey Bulletin 54: 9-22.

Corkhill, P. 1973: Manx Shearwaters on Skomer: population and mortality due to gull predation. British Birds 66: 136-143.

CYTEL 1999: EGRET ${ }^{\text {TM }}$ for Windows ${ }^{\text {TM }}$ user manual, CYTEL Software Corporation, Cambridge, Massachusetts: 296 pp.

Dunn, E.K. 1973: Changes in the fishing ability of terns associated with wind velocity and sea surface conditions. Nature 244: 520-521.

Finney, S.K., Wanless, S. \& Harris, M.P. 1999: The effect of weather conditions on the feeding behaviour of a diving bird, the Common Guillemot Uria adlge. Journal of Avian Biology 30: 23-30.

Furness, R.W. 1987: The Skuds. T \& A D Poyser, Calton: 363 pp.

Geoscience Australia 2003: Australian Government Department of Industry, Tourism and Resources. Astronomical Information (Online), available at <www.ga.gov.au/nmd/geodesy/astro> (accessed 16 January 2004).

Gould, P.J. 1967: Nocturnal feeding of Sterna fuscata and Puffinus pacificus. Condor 69: 529.

Hamer, K.C. \& Read, H. 1987: Patterns of return to land in a colony of Cory's Shearwaters Calonectris diomedea on Selvagem Grande. Seabird 10: 3-11.

Hamer, K.C., Nicholson, L.W., Hill, J.K., Wooller, R.D. \& Bradley, J.S. 1997: Nestling obesity in procellariiform seabirds: temporal and stochastic variation in provisioning and growth of Short-tailed Shearwaters Puffinus tenuirostris. Oecologia 112: 4-11.

Harper, P.C. 1972: The field identification and distribution of the Thin-billed Prion Pachyptila belcheri and the Antarctic Prion Pachyptila desolata. Notornis 19: 140-175.

Harris, M.P. 1969: The biology of storm petrels in the Galapagos Islands. Proceedings of the Californian Academy of Science 37: $95-166$.

Harris, S.W. 1974: Status, chronology and ecology of nesting storm petrels in north western California. Condor 76 : 249-261.

Imber, M.J. 1973: The food of Grey-faced Petrels Pterodroma macroptera gouldi (Hutton) with special reference to diurnal migration of their prey. Journal of Animal Ecology 42: 645-662.

Imber, M.J. 1975: Behaviour of petrels in relation to the moon and artificial lights. Notornis 22: 302-306.

Johnstone, R.E., Smith, L.A. \& Klomp, N.I. 1990: Seabird Islands No.203: Wickham Island, Archipelago of the Recherche, Western Australia. Corella 14: 131-132. 
Klomp, N.I. \& Furness, R.W. 1992: Patterns of chick feeding in Cory's Shearwaters and the association of ambient light. Colonial Waterbirds 15: 95-102.

Manuwal, D.A. 1974: The natural history of Cassin's Auklet Ptychoramphus aleuticus. Condor 74: 421-431.

MathSoft 1996: Axum $^{\mathrm{rm}}$ 5.0B Package for Windows ${ }^{\mathrm{TM}}$. MathSoft Inc. 101 Main Street, Cambridge, Massachusetts.

McNeil, R., Drapeau, P. \& Pierotti, R. 1993: Nocturnality in colonial waterbirds: occurrence, special adaptations and suspected benefits. Current Ornithology 10: 187-246.

Norušis, M.J. 1994: SPSS Advanced Statistics Manual, Release 6.1. SPSS Incorporated, Chicago: $397 \mathrm{pp}$.

Pennycuick, C.J. 1987: Flight of auks (Alcidae) and other northern seabirds compared with southern Procellariiformes: ornithodolite observations. Journal of Experimental Biology 128: 335-347.

Phillips, R.A. \& Hamer, K.C. 2000: Periodic weighing and the assessment of meal mass and feeding frequency in seabirds. Journal of Avian Biology 31: 75-80.

Powell, C.D.L., Wooller, R.D. \& Bradley, J.S. 2007: Breeding biology of the Flesh-footed Sbearwater Puffinus carneipes on Woody Island, Western Australia. Emu 107: 275-283.

Sagar, P.M. \& Sagar, J.L. 1989: The effects of wind and sea on the feeding of Antarctic Terns at the Snares Islands, New Zealand. Notornis 36: 171-182.

Schreiber E.A. 2002: Climate and weather effects on seabirds. In Schreiber, E.A \& Burger, J. (eds): Biology of Marine Birds. CRC Press, Boca Raton: 179-215.
Storey, A.E. \& Grimmer, B.L. 1986: Effect of illumination on the nocturnal activities of Manx Shearwaters: colony avoidance or inconspicuous behaviour? Bird Behaviour 6: 85-89.

Taylor, I.R. 1983: Effect of wind on the foraging behaviour of Common and Sandwich Terns. Ornis Scandinavica 14: 90-96.

Tickell, W.L.N. \& Gibson, J.D. 1968: Movements of Wandering Albatrosses Diomedea exulans. Emu 68: 7-20.

Warham, J. 1958: The nesting of the shearwater Puffinus carneipes. Auk 75: 1-14.

Warham, J. 1960: Some aspects of the breeding behaviour of the Short-tailed Shearwater. Еmu 60: 75-87.

Warham, J. 1990: The Petrels: Their Ecology and Breeding Systems. Academic Press, London: $440 \mathrm{pp}$.

Watanuki, Y. 1986: Moonlight avoidance behaviour in Leach's Storm-petrels as a defence against Slaty-backed Gulls. Auk 103: 14-22.

Weimerskirch, H. \& Wilson, R.P. 1992: When do Wandering Albatrosses Diomedea exulans forage? Marine Ecology Progress Series 86: 297-300.

Zar, J.H. 1999: Biostatistical Analysis (4th edn). Prentice-Hall, New Jersey: 663 pp.

(accepted 5 August 2008) 